\title{
Evaluation of the morphological and clinical features of left anterior descending myocardial bridging with multi-detector computed tomography
}

\author{
Neşat Çullu¹, ibrahim Önder Yeniçeri ${ }^{1}$, Murat Yunus Özdemir ${ }^{1}$, ilknur Altun², Emrah Doğan ${ }^{1}$ \\ ${ }^{1}$ Faculty of Medicine, Muğla Sıtkı Koçman University, Muğla, Turkey \\ 2Department of Radiology, Muğla Training and Research Hospital, Muğla, Turkey
}

Kardiochirurgia i Torakochirurgia Polska 2021; 18 (2): 87-91

\begin{abstract}
Aim: The aim of the study was to assess the incidence, localization, depth, length of myocardial bridging (MB) with left anterior descending (LAD), systolic compression ratio, atherosclerotic plaque localization and degree of stenosis by 256 -slice multidetector computed tomography (MDCT).

Material and methods: Computed tomography (CT) scans from a total of 3947 patients who underwent MDCT were reviewed retrospectively for $L A D M B$. A diastolic and systolic dataset with the best image quality was selected. Myocardial bridge was defined as a coronary artery with an intra-myocardial course. Myocardial bridging was divided into "deep" or "superficial". The length and depth of the bridging segment were calculated. For each bridging segment, the presence of atherosclerosis was saved in a 2-cm-long segment proximal to the entry of the bridging segment. The degree of stenosis made by atherosclerotic plaques was determined.

Results: LAD myocardial bridging was detected in 410 (10.4\%) patients. Among these, 97 (23.7\%) patients had a deep and 313 (76.3\%) patients had a superficial course. The mean LAD MB length was $20.28 \pm 9.63 \mathrm{~mm}$ and the depth was $1.72 \pm 1.11 \mathrm{~mm}$. The systolic and diastolic mean diameter difference was $0.193 \mathrm{~mm}$ and the average compression ratio was $9.44 \%$. Atherosclerotic plaques were found in 167 (40.7\%) of 410 LAD MB. Atherosclerotic plaques were found in $50.5 \%$ of deep MB and $37.7 \%$ of superficial MB. Conclusions: 256 -slice MDCT coronary angiography has a high sensitivity to show myocardial bridging in LAD localization, to determine length, depth, compression ratio, atherosclerotic plaque localization and degree of stenosis.
\end{abstract}

Key words: left anterior descending myocardial bridging, multi-detector computed tomography, coronary artery.

\section{Introduction}

Myocardial bridging (MB) is an intramuscular course of a normal epicardial coronary artery first identified by Reyman in 1737 in autopsy series. In 1960, angiographic features were defined by Portman and Ivigin [1]. The ratio of $\mathrm{MB}$ in the general population varies in the range $0.5-4.5 \%$ in angiography series and $15-85 \%$ in autopsy series [2-4]. In addition, it constitutes $76.9 \%$ of left anterior descending (LAD), $10 \%$ of right coronary artery (RCA) and $6.7 \%$ of left circumflex (LCX). It usually appears in the mid-section of the LAD coronary artery (46.7\%) [4-6].

$M B$ is often considered a harmless anatomical variant of the coronary artery. But MB can cause myocardial ischemia, rhythm disorder and sudden death [7-10].

In the diagnosis of $\mathrm{MB}$, catheter coronary angiography is the gold standard. Low detection of MB in coronary angiography may be because of superficial bridging. Coronary angiography and intravascular ultrasound (IVUS) are inva- sive methods and involve various risks. In addition, both methods are costly and are not routinely used in clinical practice. Multi-detector computed tomography (MDCT) coronary angiography is rapid and sufficient for diagnosis. MDCT can evaluate the course of coronary artery and its relationship with other anatomical structures [11, 12].

\section{Aim}

The goal of this study was to assess the incidence, localization, depth, length of MB with LAD, systolic compression ratio, atherosclerotic plaque localization and degree of stenosis by 256 -slice MDCT.

\section{Material and methods \\ Study population}

The retrospective study was done in our university's Radiology Department. This study was confirmed by the ethics

Address for correspondence: Neşat Çullu, Faculty of Medicine, Muğla Sıtkı Koçman University, Muğla, Turkey, phone: +90 5072030472,

e-mail: nesatcullu77@gmail.com

Received: 26.01.2021, accepted: 14.03.2021. 
council of our university. The patient population comprised 410 consecutive patients (159 female; 251 male, mean age: $55.99 \pm 12.24$ years; range: $16-90$ years) who underwent coronary angiography with MDCT. Patients were sent for MDCT angiography because of clinically suspicious coronary artery disease. Patients with atypical chest pain, family history of coronary artery disease, smoking, high cholesterol and lipid levels, previous coronary artery disease and coronary $\mathrm{CT}$ angiography were included in the study. Exclusion situations for MDCT were decided as allergy to iodinated contrast agent, gravidity, renal failure and arrhythmia. Non-diagnostic images were excluded from this study. 140 patients were excluded because of inadequate imaging due to patient characteristics (obesity, respiratory incontinence and high pulse) and movement artifacts. The study flow chart is shown in Figure 1.

\section{MDCT imaging protocol}

MDCT images were obtained using a 256-slice dual energy CT scanner (Siemens Definition Flash, Berlin, Germany). The imaging parameters were $256 \times 0.75 \mathrm{~mm}$ detector collimation, pitch 0.23 , rotation time $400 \mathrm{~ms}$, tube voltage $120 \mathrm{kV}$ and current $320 \mathrm{mAs}$. ECG-induced tube current modulation was performed in rhythmic heart beats. During the middle inspiratory breath-hold, the single scan direction was craniocaudal. The scan range covered all the heart to the diaphragm of the tracheal bifurcation level. A bolus of $100 \mathrm{ml}$ of iodinated contrast medium ioversol (Optiray 350 mg/ml; Guerbet, France) was administered intravenously to an antecubital vein at a flow rate of $5-6 \mathrm{ml} / \mathrm{s}$ using a double-headed power injector. Then $50-60 \mathrm{ml}$ of salt solution $(5 \mathrm{ml} / \mathrm{s})$ was given. The imaging was started automatically by applying the "sure start" method (left atrium, threshold $130 \mathrm{HU}$ ). If the heart beat is greater than 65 beats per minute, oral $\beta$-blockers are given before MDCT screening.



Figure 1. Flow chart of patient inclusion and exclusion

CCTA - coronary computed tomography angiography, CA - catheter angiography, $\mathrm{MB}$ - myocardial bridging.

\section{Image analysis}

Retrospective reconstructions were used in whole cardiac phases with $10 \%$ steps of the R-R interval. Images were reconstructed with a slice thickness of $0.75 \mathrm{~mm}$, a reconstruction increase of $0.3 \mathrm{~mm}$, image matrix $512 \times 512$, and an field of view (FOV) of 180-240 mm. Data were transferred to the Syngo Via workstation (Siemens, Berlin, Germany). A diastolic and systolic dataset with the best image quality was selected. Images were restructured using multiple post-processing methods. Transverse source images, multiplanar reformations (MPR), curved multiplanar reformations and maximum intensity projection images were used for evaluating the intramyocardial course. Myocardial bridge was defined as the coronary artery with intra-myocardial course. MDCT images were assessed by single radiologists experienced in cardiovascular radiology.

Myocardial bridging was divided into two types: 'deep' and 'superficial'. Deep myocardial bridging was identified as full LAD (depth $\geq 2 \mathrm{~mm}$ ) (Figure 2) surrounded by myocardium. Superficial bridging was defined as the surface not completely covered by myocardial fibers (depth $<2 \mathrm{~mm}$ ) (Figure 3) $[13,14]$. Location of the LAD (proximal, middle, and distal) MB segment was saved. The length and depth of the bridging segment were calculated with the digital caliper on the curved MPR. The diameter of each bridging segment was measured at the end of the diastolic and systole phase in curved MPR. The systolic compression difference and percentage were calculated from the average of the measurements in two different phases. For each bridged segment, the presence of atherosclerosis was

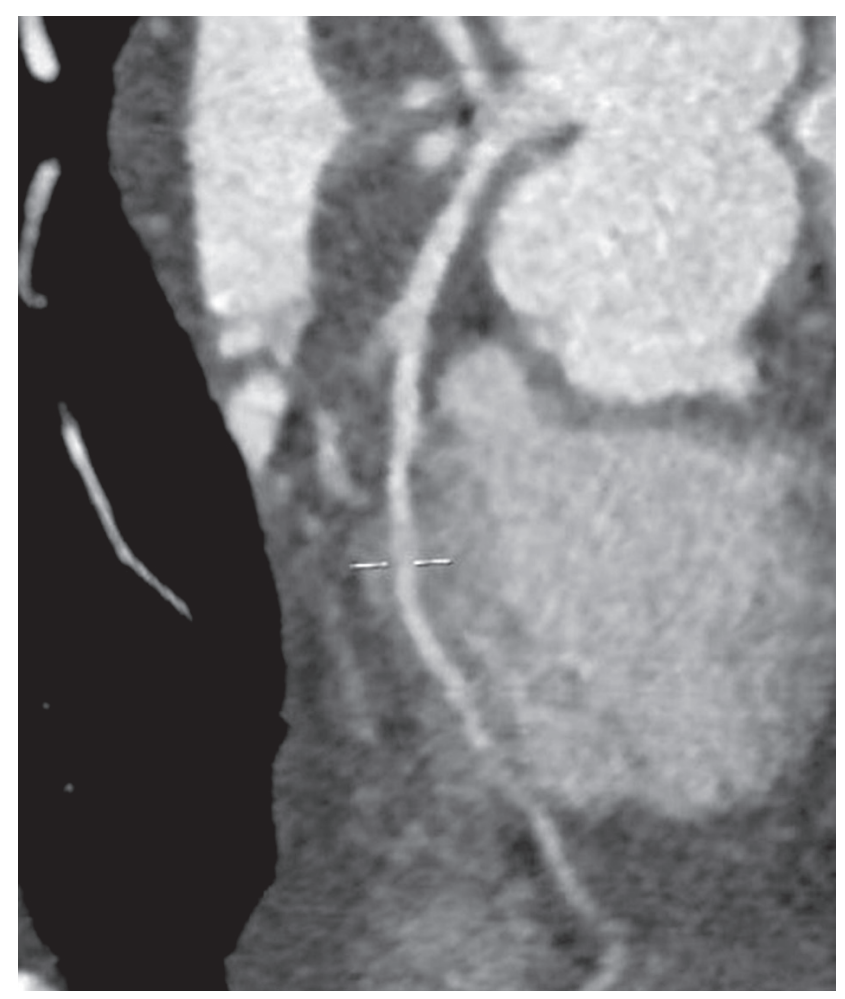

Figure 2. LAD middle segment long segment deep myocardial bridging 




Figure 3. LAD mid segment short segment deep myocardial bridging

saved in a 2-cm-long part proximal to the entrance of the bridging segment. The degree of stenosis made by atherosclerotic plaques was determined. It was defined as mild stenosis below $50 \%$, moderate stenosis of $50-70 \%$ and severe stenosis over $70 \%$.

\section{Statistical analysis}

Statistical evaluation was performed using the IBM SPSS version 18.0 software (SPSS Inc., Chicago, III., USA). Descriptive data are expressed as mean \pm standard deviation. Results were evaluated at the $95 \%$ confidence interval and $p<0.05$ significance level.

\section{Results}

A total of 3947 patients who underwent coronary CT angiography in our hospital between 2017 and 2019 were retrospectively evaluated. LAD myocardial bridging was detected in 410 (10.4\%) patients. The mean age of the patients was $55.99 \pm 12.24$ years. Demographic and plaque characteristics of patients with LAD MB are shown in Table I. Table II shows location and depth type of myocardial bridging in LAD coronary arteries. Depth, length, systolic and diastolic coronary artery diameters of LAD myocardial bridging are given in Table III. The systolic and diastolic mean diameter difference was $0.193 \mathrm{~mm}$ and the average compression ratio was $9.44 \%$.

Atherosclerotic plaques were found in 167 (40.7\%) of 410 LAD MB. Atherosclerotic plaques were found in $50.5 \%$
Table I. Demographic and atherosclerotic plaque characteristics of patients with myocardial bridges in LAD coronary arteries

\begin{tabular}{lc}
\hline Parameter & MB patients $n(\%)$ \\
\hline Age [years] & $55.99 \pm 12.24$ \\
\hline Gender (M/F) & $251 / 159(61.2 / 38.8)$ \\
\hline Hypertension & $169(41.2)$ \\
\hline Hyperlipidemia & $195(47.6)$ \\
\hline Diabetes & $79(19.3)$ \\
\hline Smoking & $41(10)$ \\
\hline Indication for CCTA: & $57(13.9)$ \\
\hline Typical chest pain & $199(48.5)$ \\
\hline Atypical chest pain & $67(16.3)$ \\
\hline Presence of risk factors & $41(10)$ \\
\hline Known CAD & $41(10)$ \\
\hline Arrhythmia & $5(1.2)$ \\
\hline Valvular heart disease & $243(59.3)$ \\
\hline Presence of plaque: & $112(27.3)$ \\
\hline No & $26(6.3)$ \\
\hline Calcific & $29(7.1)$ \\
\hline Soft & $126(30.7)$ \\
\hline Mixed & $24(5.9)$ \\
\hline Stenosis: & $17(4.1)$ \\
\hline No & \\
\hline Mild & \\
\hline Severe & \\
\hline
\end{tabular}

Table II. Location and depth type of myocardial bridging in LAD coronary arteries

\begin{tabular}{lcc}
$\begin{array}{l}\text { Myocardial bridging } \\
\text { Location: }\end{array}$ & $n$ & $\%$ \\
\hline \begin{tabular}{l} 
Proximal \\
\hline Middle
\end{tabular} & 6 & 1.5 \\
\hline Distal & 366 & 89.3 \\
\hline \begin{tabular}{l} 
Type: \\
\hline Deep
\end{tabular} & 38 & 9.3 \\
\hline Superficial & 97 & 23.7 \\
\hline
\end{tabular}

Table III. Measurements of myocardial bridging in LAD coronary arteries

\begin{tabular}{lcc} 
Parameter & Mean \pm SD & $\%$ \\
Dept $[\mathrm{mm}]$ & $1.72 \pm 1.11$ & \\
\hline Length $[\mathrm{mm}]$ & $20.28 \pm 9.63$ & \\
\hline Systolic $[\mathrm{mm}]$ & $1.82 \pm 0.17$ & $9.44(0.193 \mathrm{~mm})$ \\
\hline Diastolic $[\mathrm{mm}]$ & $2.02 \pm 0.19$ & \\
\hline
\end{tabular}


of deep MB and $37.7 \%$ of superficial MB. $76.2 \%$ of atherosclerotic plaques were calcific, $15.5 \%$ soft and $17.4 \%$ mixed. Atherosclerotic plaques caused mild stenosis in $75.5 \%$, moderate stenosis in $14.4 \%$ and severe stenosis in $10.2 \%$ (Table I). Ninety-one percent of atherosclerotic plaques were present in the middle segment $M B, 7.2 \%$ distal and $1.8 \%$ proximal MB.

\section{Discussion}

In many studies, LAD bridging rates and depth types differ according to race, geographic region, and gender. Jin et al. [13] detected LAD myocardial bridging in 557 (42\%) patients in their study in 1275 patients. Superficial MB was found in 368 (66\%) patients and deep MB in 189 (34\%) patients. Superficial MB was complete in 128 (35\%) and incomplete in 240 (65\%). Jodocy et al. [14] found LAD MB in 51 (23\%) of 221 patients. Aydın et al. [15] found LAD MB in 41 (21.5\%) patients in their study in 191 patients. In this study, the deep $M B$ ratio was $39 \%$ and the superficial MB ratio was $61 \%$. Çay et al. [16] found 316 patients with myocardial bridging among 25982 patients. Total prevalence was $1.22 \%$. Although myocardial bridging had lesions in the left anterior descending coronary artery as expected in $96.52 \%$ of patients, the distribution of the bridging in the middle and distal regions was almost equal (52.9\% and $47.21 \%$, respectively). In the study of Ma et al. [17], MB was detected in the LAD in 325 (13.2\%) of 2462 patients. The LAD MB rate was $60.4 \%$ among MB patients. Donkol and Saad [18] found MB in 89 of 350 patients. $76.4 \%$ of these MBs were in the middle LAD and $14.6 \%$ were in the distal LAD. In this study, 46 (61.3\%) LAD MB were superficial and 29 (38.7\%) were the deep type. Atar et al. [19] found MB in 25 of 165 patients. Among these, LAD MB was detected in 21 (60\%) patients. In our study, a total of 4100 coronary CT angiographies were evaluated retrospectively. The mean age of the patients was 56 years. $61.2 \%$ of the patients were male. LAD MB was detected in 410 (10\%) patients. Among these, LAD MD was detected in the proximal segment in $8(1.5 \%)$ patients, in the middle segment in 366 patients (89.1\%), and in the distal segment in $38(9.3 \%)$ patients. Among these, 97 (23.7\%) patients had deep and $313(76.3 \%)$ patients had superficial course.

Depth, length and systolic-diastolic diameters and compression percentage of myocardial bridging are important for the development of symptoms. Ma et al. [17] found that the mean length of LAD MB was $18.1 \pm 6.1 \mathrm{~mm}$ and the depth was $2.9 \pm 0.8 \mathrm{~mm}$. They found that arterial diameter in the ED phase was $2.6 \pm 0.5 \mathrm{~mm}$ and ES artery diameter was $1.5 \pm 0.3 \mathrm{~mm}$. The change in mean systolic-diastolic diameter was $1.1 \pm 0.4 \mathrm{~mm}$ and compression percentage ranged from $34.9 \%$ to $50 \%$. In the study of Ercakmak et al. [20], MB length was found to be between 8 and $50 \mathrm{~mm}$ and depth between 0.7 and $4.5 \mathrm{~mm}$ in $\mathrm{CT}$ angiography. Jodocy et al. [14] found that the LAD MB length was $14.9 \pm 6.5 \mathrm{~mm}$ and the depth was $2.6 \pm 1.6 \mathrm{~mm}$. They found an average reduction in arterial diameter in the systolic phase of $27 \%$ and in the end diastolic phase of $15 \%$. They detected luminal narrowing above $50 \%$ in $8 \%$ of patients. Zhang et al.
[21] found that the narrowing of the arterial lumen was between $14 \%$ and $36 \%$ on average. In the study of Donkol and Saad [18], mean length of MB was $15 \pm 7 \mathrm{~mm}$ (min.-max. 6-24 mm) and mean diameter was $3 \pm 3 \mathrm{~mm}$ for the LAD. Dynamic compression was observed in 35 patients. However, no signs of hypoperfusion were observed. Chen et al. [22] found as $21.1 \pm 7.3 \mathrm{~mm}$ and $3.60 \pm 1.47 \mathrm{~mm}$ in the middle segment, and $22.1 \pm 10.8 \mathrm{~mm}$ and $3.12 \pm 2.39 \mathrm{~mm}$ in the distal segment the mean LAD MB length and depth. Hwang et al. [13] found a superficial length of $16.4 \pm 8.6 \mathrm{~mm}$ in the LAD MB. The length of the deep MB was $27.6 \pm 12.8 \mathrm{~mm}$ and the depth was $3.0 \pm 1.4 \mathrm{~mm}$. In our study, the mean LAD MB length was $20.28 \pm 9.63 \mathrm{~mm}$ and the depth was 1.72 $\pm 1.11 \mathrm{~mm}$. The mean systolic diameter reduction was approximately $10 \%$. The clinical course of patients with LAD bridging has changed in terms of symptoms. Drug therapy was administered to those patients. After the administration of these drugs, the complaints of patients have mitigated, and patients' life quality has increased.

There is a relationship between myocardial bridged coronary segments and atherosclerotic plaque. In the study of Hwang et al. [13], atherosclerotic plaques were associated with MB in 175 (31\%) of 557 tunneled segments. In their study, most atherosclerotic plaques were located at the segment proximal to the MB segment, with a rate of $91 \%$. Atherosclerotic plaques were found in 17 of the complete superficial type, in 29 of the incomplete superficial type, and in 41 of the deep type. In the study of Aydın et al. [15], the proportion of atherosclerotic plaques in the proximal segment of the LAD MB was $49 \%$. Mild and moderate CAD was found in 11 and 9 cases respectively. Mixed atheroma plaques were seen in 17 of 20 cases. Soft plaques were monitored in only 3 cases. Atherosclerotic plaque and stenosis were not detected in the LAD bridging segment. Atherosclerotic plaques were found in 167 (40.7\%) of 410 LAD $M B$. Atherosclerotic plaques were more frequent in deep MB than in superficial MB. Atherosclerotic plaques mostly caused mild stenosis. The moderate to severe stenosis rate was $24.6 \%$. In the LAD MB middle segment, the rate of atherosclerotic plaque was higher than the others.

This study has some limitations. The first is that it is single-centered and retrospective. Second, intra-interobserver variability was not evaluated in the study.

\section{Conclusions}

256-slice MDCT coronary angiography has a high sensitivity to show myocardial bridging in LAD localization, to determine length, depth, compression ratio, atherosclerotic plaque localization and degree of stenosis.

\section{Disclosure}

The authors report no conflict of interest.

\section{References}

1. Porstmann W, Iwig J. Intramural coronary vessels in the angiogram. Fortschr Geb Rontgenstr Nuklearmed 1960; 92: 129-33. 
2. Irvin RG. The angiographic prevalence of myocardial bridging in man. Chest 1982; 81: 198-202.

3. Ge J, Jeremias A, Rupp A, Abels M, Baumgart D, Liu F, Haude M, Görge G, von Birgelen C, Sack S, Erbel R. New signs characteristic of myocardial bridging demonstrated by intracoronary ultrasound and Doppler. Eur Heart J 1999; 20: 1707-16.

4. Alegria JR, Herrmann J, Holmes DR Jr, Lerman A, Rihal CS. Myocardial bridging. Eur Heart J 2005; 26: 1159-68.

5. Möhlenkamp S, Hort W, Ge J, Erbel R. Update on myocardial bridging. Circulation 2002; 106: 2616-22.

6. Ishii T, Hosoda Y, Osaka T, Imai T, Shimada H, Takami A, Yamada H. The significance of myocardial bridge upon atherosclerosis in the left anterior descending coronary artery. J Pathol 1986; 148: 279-91.

7. Kramer JR, Kitazume H, Proudfit WL, Sones FM Jr. Clinical significance of isolated coronary bridges: benign and frequent condition involving the left anterior descending artery. Am Heart J 1982; 103: 283-8.

8. Uhm JS, Park CS, Kim TS, Kim SY, Kim HJ, Park YK, Kim JH, Oh YS, Youn HJ, Chung WS, Hong SJ. A case of acute myocardial infarction caused by coronary thrombus associated with a myocardial bridge and slow coronary flow. Korean Circ J 2005; 35: 639-42.

9. Lee JH, Bae Y, Lee HS, Kim BH, Yeum SM, Chae DL, Kim SP, Jun WJ, Cho JH. A case of myocardial infarction in a patient with myocardial bridge and atrial fibrillation. Korean Circ J 2004; 34: 319-22.

10. Cutler D, Wallace JM. Myocardial bridging in a young patient with sudden death. Clin Cardiol 1997; 20: 581-3.

11. Junbo G, Jianying M. Detection Myocardial Bridging Using Non-Invasive Technique. Prof. Baskot Branislav (Ed.), 2011 ISBN: 978-953-307-675-1.

12. Hazirolan T, Canyigit M, Karcaaltincaba M, Dagoglu MG, Akata D, Aytemir K, Besim A. Myocardial bridging on MDCT. AJR Am J Roentgenol 2007; 188: 1074-80.

13. Hwang JH, Ko SM, Roh HG, Song MG, Shin JK, Chee HK, Kim JS. Myocardial bridging of the left anterior descending coronary artery: depiction rate and morphologic features by dual source CT coronary angiography. Korean J Radiol 2010; 11: 514-21.

14. Jodocy D, Aglan I, Friedrich G, Mallouhi A, Pachinger O, Jaschke W, Feuchtner GM. Left anterior descending coronary artery myocardial bridging by multislice computed tomography: correlation with clinical findings. Eur J Radiol 2010; 73: 8995.

15. Aydın A, Çubuk R, Atasoy MM, Gurol T, Soylu O, Dagdeviren B. The morpho logic and functional features of LAD myocardial bridging at multi detector computed tomography coronary angiography: correlation with coronary artery disease. Arch Turk Soc Cardiol 2015; 43: 31-7.

16. Çay S, Öztürk S, Cihan G, Kisacik HL, Korkmaz S. Angiographic prevalence of myocardial bridging. Anadolu Kardiyol Derg 2006; 6: 9-12.

17. Ma E, Ma G, Yu HW, Wu W, Li K. Assessment of myocardial bridge and mural coronary artery using ECG-gated 256-slice CT angiography: a retrospective study. Sci World J 2013; 2013: 947876

18. Donkol RH, Saad Z. Myocardial bridging analysis by coronary computed tomographic angiography in a Saudi population. World J Cardiol 2013; 5: 434-41.

19. Atar E, Kornowski R, Fuchs S, Naftali N, Belenky A, Bachar GN. Prevalence of myocardial bridging detected with 64-slice multidetector coronary computed tomography angiography in asymptomatic adults. J Cardiovasc Comput Tomogr 2007; 1: 78-83.

20. Ercakmak B, Bulut E, Hayran M, Kaymaz F, Bilgin S, Hazirolan T, Bayramoglu A, Erbil M. Comparison of radiological and morphologic assessments of myocardial bridges. Anat Sci Int 2015; 90: 222-8.

21. Zhang LJ, Yang GF, Zhou CS, Huang W, Lu GM, Shiroishi MS. Multiphase evaluation of myocardial bridging with dual-source computed tomography. Acta Radiol 2009; 50: 775-80.

22. Chen YD, Wu MH, Sheu MH, Chang CY. Myocardial bridging in taiwan: depiction by multidetector computed tomography coronary angiography. J Formos Med Assoc 2009; 108: 469-74. 